A N N A L E S Annales de Bretagne et des Pays de l'Ouest

\title{
Aremorica. Études sur l'ouest de la Gaule romaine
}

\section{Nicolas Mathieu}

\section{(2) OpenEdition}

Journals

Édition électronique

URL : https://journals.openedition.org/abpo/6879

DOI : $10.4000 / a b p o .6879$

ISSN : 2108-6443

\section{Éditeur}

Presses universitaires de Rennes

\section{Édition imprimée}

Date de publication : 30 juin 2021

Pagination : 201-203

ISBN : 978-2-7535-8359-7

ISSN : 0399-0826

\section{Référence électronique}

Nicolas Mathieu, "Aremorica. Études sur l'ouest de la Gaule romaine», Annales de Bretagne et des Pays de I'Ouest [En ligne], 128-2 | 2021, mis en ligne le 30 juin 2020, consulté le 23 octobre 2022. URL : http:// journals.openedition.org/abpo/6879; DOI : https://doi.org/10.4000/abpo.6879 


\section{Comptes-rendus}

Aremorica. Études sur l'ouest de la Gaule romaine, 9, 2018, Brest, Centre de recherche bretonne et celtique (CRBC), 2018. 189 p., index des noms de lieux. ISBN : 97910-92331-41-7. $23 €$.

La neuvième livraison d'Aremorica contient sept articles d'origines diverses. Dans la suite du numéro précédent (compte rendu dans $A B P O, 125$, 4, p. 167-170), deux articles dérivent de la $11^{\mathrm{e}}$ journée d'étude tenue à Locmariaquer en avril 2016 (M. Demarest et al.; É. Guézennec), trois sont issus de la $12^{2}$ journée d'étude tenue à Brest ou en dérivent (Fl. Blanchard; G. Schütz; M. Mauger). Ont été ajoutés deux articles (B. Watrin; Y. Maligorne). Comme il arrive depuis quelques numéros, les territoires septentrionaux sont aussi couverts par cette livraison qui mêle des enquêtes ponctuelles récentes résultant de prospections ou de fouilles et des synthèses et mises au point thématiques ou méthodologiques bienvenues. On retrouve, comme dans les numéros précédents une mise en page soignée et sobre où les images (cartes, plans, dessins) sont très lisibles. Tous les auteurs ont situé leurs études dans la cité antique correspondante, ce qui est indispensable et ce dont il faut les remercier. Pour améliorer la qualité de la publication en facilitant le travail des historiens lecteurs, il faudrait que tous les auteurs prennent l'habitude de mentionner les documents épigraphiques en indiquant les corpus épigraphiques selon les normes usuelles internationales (quitte à livrer une liste des abréviations pour permettre aux non spécialistes de s'y retrouver : $C I L, I L A$, etc.) et L'Année épigraphique (AE). On sait gré aux archéologues d'avoir, comme il convient à la première mention, écrit " nombre minimum d'individus " avant d'abréger NMI, dans la suite de l'article, qui est lu par conséquent facilement par les non archéologues (p. 41). Trois articles présentent des sites; un livre une identification d'un monument connu; trois consistent en synthèses thématiques.

L'apport des images satellites à la connaissance d'un site est illustré par l'article de B. Watrin, « Le site antique du Bout Levet à Saint-André-sur-Cailly (Seine-Maritime) : l'apport des images satellites ", p. 9-15, situé à une quinzaine de kilomètres au nord-nord-est du chef-lieu de la cité des Véliocasses (Rouen / Rotomagus). Au théâtre, révélé au XIX ${ }^{\mathrm{e}}$ siècle, les images satellites (Microsoft Bing et Géoportail) ont ajouté de nouveaux bâtiments : au nord-ouest, un ensemble monumental d'au moins $60 \mathrm{~m}$ de côté qui fait penser à un sanctuaire et autour de cet ensemble monumental comprenant aussi le théâtre, de l'est à l'ouest en passant par le sud, des bâtiments dont plusieurs à galerie en façade. L'aire de ce site, de 70 ha, le caractère monumental des édifices, la décoration et l'organisation topographique conduisent à s'interroger sur la possibilité d'un complexe cultuel à caractère public.

M. Demarest, A. Lacroix, M.-A. Thierry : " Un dépotoir du III $^{\mathrm{e}}$ siècle apr. J.-C. dans le quartier du théâtre à Vieux (Calvados) ", p. 38-70, présentent le résultat d'une fouille sous la forme d'une étude croisée du mobilier en dépôt secondaire trouvé dans une cave désaffectée, située au nord-est de la ville, à l'est de l'édifice de spectacle, transformée en dépotoir. De la vaisselle (céramiques, verre) à l'outillage 
(couteau, poids, aiguilles, alêne, illustrant le travail du cuir, outils abrasifs etc.) en passant par des témoignages sur l'armement (javeline, bouterolle), la vie spirituelle (fragment de statuette de déesse-mère en terre cuite blanche), sociale ou domestique (boîte à sceau, pion, jetons en os), le mobilier (pièces de serrurerie, fragments d'enduits peints, de mortier d'opus sectile), le vêtement ou la parure (épingles à cheveux mais absence de fibule : usage de vêtements cousus?), ce dossier montre la complémentarité de la vaisselle en céramique et en verre dans la sphère domestique - avec un usage du verre pour la vaisselle de table -, vient confirmer des traits observés dans les ensembles mobiliers domestiques dans la cité dans la première moitié du III ${ }^{\text {e }}$ siècle apr. J.-C. et conduit à s'interroger sur la présence à un moment d'un occupant peut-être " fonctionnaire d'État " civil ou militaire (p. 70).

Un autre exemple de résultats d'une fouille, préventive, est fourni par G. Schütz, "Bayeux (Calvados), 51-53 rue de la Bretagne : occupation gallo-romaine dans le suburbium nord du chef-lieu des Baïocasses ", p. 71-84, dans le secteur périphérique septentrional du chef-lieu de la cité. Des six phases d'occupation successives allant de l'Antiquité à l'époque moderne, la période gallo-romaine est la plus riche. Les premiers indices concernent la première moitié du Ir siècle apr. J.-C. (rejets d'ossements de bovins et d'ovicaprins témoignant d'une préparation de carcasses pour une consommation ailleurs, donc d'une activité de boucherie), puis dans la seconde moitié de ce siècle d'une occupation avec habitation construite sur solins. Au cours du II ${ }^{\mathrm{e}}$ siècle a été construit un bâtiment qui a connu plusieurs états et finalement une citerne dont la fouille n'a pas permis de définir pour quels besoins. Dans la première moitié du $\mathrm{III}^{\mathrm{e}}$ siècle ou au milieu de celui-ci, le bâtiment a été abandonné. Par comparaison avec ce qui était connu plus au nord et présentait un caractère rural, les données de la fouille contribuent ainsi à mieux connaître les limites septentrionales de l'extension urbaine.

Fl. Blanchard avec la collaboration de J. et M.-H. Santrot, présente " Un monument déplacé : un autel à quatre dieux provenant du Châtelet de Gourzon (HauteMarne) dans les jardins de la Garenne Lemot (Loire-Atlantique) ", p. 17-38. Cette réattribution est le fruit du long travail de recherche historiographique qui accompagne toute fabrication ou mise à jour de corpus, ici le Nouvel Espérandieu, entreprise collective sous les auspices de l'Académie française et la direction d'H. Lavagne, dans son volume consacré à la cité des Pictons, un siècle après le $R e$ cueil général des bas-reliefs, statues et bustes de la Gaule romaine, dirigé par Émile Espérandieu. À l'identification précise des figures sculptées en relief sur chacune des faces (une figure féminine tenant une lourde bourse, vraisemblablement une parèdre de Mercure, Maia ou Rosmerta; une autre aux attributs difficilement identifiables, peut-être une divinité topique; la déesse Victoria; Hercule et le lion de Némée), doit être ajoutée, par l'observation précise du sommet, l'identification d'un autel et non d'un couronnement de monument plus haut de type pilier.

M. Mauger, livre des "Réflexions méthodologiques sur les cultes domestiques dans l'Ouest de la Gaule ", p. 84-102. Son point de départ, apparemment simple : "l'ensemble des pratiques cultuelles réalisées au sein de l'espace domestique " (p. 86), montre les difficultés à appréhender, interpréter le mobilier découvert, notamment de type laraire. Plaidoyer pour la constitution de corpus régionaux avant d'envisager des comparaisons, les modèles pompéiens et vésuviens n'étant pas totalement pertinents ou utilisables dans l'ouest des Gaules, l'article invite de manière convaincante à ne pas plaquer de grilles de lecture étrangères aux sites étudiés. Les villas des contrées occidentales des Gaules ne sont pas celles de l'Italie nonobstant des formes, des plans ou des parties qui peuvent y trouver des parallèles ponctuels, presque uniquement d'ailleurs pour les maisons de notables, à péristyle. 
"Le décor architectonique dans les cités de l'Ouest de la Gaule d'Auguste aux Sévères ", auquel s'intéresse Y. Maligorne, p. 103-150, est celui de sept cités de l'Ouest de la Lyonnaise (Osismes, Vénètes, Coriosolites, Riédons, Namnètes, Diablintes, Andécaves), cadre de sa thèse, publiée en 2006 (L'architecture romaine dans l'Ouest de la Gaule, Rennes, PUR). L'auteur revient sur certains documents, complète le dossier par les découvertes survenues depuis, établit la chronologie. Les indices les plus anciens datent de l'époque triumvirale (à Jublains et Angers), cependant que Corseul, Rennes, Vannes, Carhaix et Nantes semblent être des créations augustéennes initiées au moment du séjour du prince dans les provinces gauloises en 16-13 av. J.-C. Les témoignages les plus anciens sont rares et semblent appartenir à des programmes édilitaires privés, non à des programmes publics. Cette hypothèse, fondée sur l'analyse fine des fragments, mérite toute notre attention car elle permet de bien faire entrer ces cités dans le concert du reste de la Lyonnaise en particulier et plus généralement de la transition entre la conquête romaine et l'intégration. L'archéologie est indispensable à la connaissance historique surtout quand les sources écrites sont peu nombreuses, éparses et dispersées. Les grands et plus nombreux programmes édilitaires publics commencent à la fin de la période Julio-claudienne et au début des Flaviens. Pour cette période et jusqu'au début du II siècle, l'étude montre l'influence de l'Urbs et le passage par l'Aquitaine de certains modèles. Elle montre aussi que des lapidarii de ces cités se sont parfois contentés de reproduire des éléments d'architecture très simples dont les moulures à elles seules constituent le décor ; ce qui ne signifie pas que ces cités sont restées à l'écart des grands courants culturels. En témoigne le sanctuaire du HautBécherel chez les Coriosolites, très vraisemblablement leur lieu de culte poliade, qui, n'ayant que des ordonnances décoratives toscanes et ne se distinguant pas en cela des domus, villas et autres édifices commerciaux de la cité, n'en emprunte pas moins sa typologie à des modèles prestigieux : templum Pacis et sanctuaire du Cigognier à Avenches. Le contexte économique local avec des disponibilités financières plus limitées que dans d'autres cités, celui des matières premières locales (quasi absence de roches sédimentaires), n'ont pas empêché les notables locaux d'être réceptifs à de grands modèles romains. Il faut donc relativiser l'importance du décor architectonique comme marqueur de "romanisation ". Ce faisant, il faut donc aussi considérer que la "romanisation " est multiforme.

É. Guézennec étudie "Les édifices de spectacles de Lyonnaise occidentale ", p. 150-180, sous la forme d'un état des lieux bibliographique et historiographique là où F. Ferreira, dans la même revue, en 2017 (p. 57-71), avait envisagé, entre autres, leur chronologie. Dimensions, morphologie, matériaux de construction les distinguent des modèles augustéens italiens.

De même qu'il n'est d'épigraphie que locale, comme l'écrivit en son temps P. Le Roux dans sa thèse, il n'est d'archéologie que locale et de bonne pratique historienne que celle qui inlassablement reprend des dossiers en usant d'échelles différentes. Fruits de travaux collectifs directement ou indirectement (par la participation à des projets collectifs de recherche, des PCR, ou à des entreprises de longue haleine comme le Nouvel Espérandieu, NEsp.), de travaux préparatoires (dans le cadre d'une thèse) ou de reprises de dossiers déjà constitués, les articles de cette livraison donnent le ton d'une recherche aujourd'hui marquée par la combinaison d'une discipline affirmée et maîtrisée et de l'échange avec d'autres disciplines. C'est aussi le signe, heureux, d'une plus grande maturité et ouverture en histoire ancienne du monde romain. 